\title{
Enhancing Instruction to Connect with Diverse Audiences ${ }^{1}$
}

Lisa A. Guion²

This paper is the tenth in a series of articles on planning programs to effectively outreach to diverse audiences. This series will include specialized papers on enhancing cultural competence, recruiting diverse volunteers, planning culturally appropriate marketing strategies, and other topics that are integral to the design and implementation of culturally relevant Extension education programs.

\section{Overview}

The social science literature reveals that a person's way of thinking, behaving, and being are deeply influenced by such factors as race/ethnicity, social class, language and other cultural constructs (Banks, J. A., Cookson, P., Gay, G., \& Whawley, W. D. 2001; Shade, 1997; Villegas and Lucas, 2002). Likewise, the preferred way in which information is delivered is also closely tied to social constructs (Banks, J. A., Cookson, P., Gay, G., \& Whawley, W. D. 2001 and many others who study this topic). In other words, an individual's learning style, in most cases, is culturally influenced. The degree that the style is influenced by culture depends on the individual's level of ethnicity, which is contingent upon many environmental, economic, and social factors (For more information on level of ethnicity see EDIS fact sheet FY758, "Ethnic Marketing: A Strategy for Marketing Programs to Diverse Audiences"). Thus, educators must identify the learning style preference of the diverse clientele they wish to reach.

Enhancing instruction to connect with diverse audiences begins with an awareness of your own preferred learning and teaching styles as well as respect for the way different cultural groups or individuals may prefer to receive, give, and process information (i.e., learn). Educators tend to teach the way they prefer to learn. If they are highly visual learners, then they tend to use a lot of visual aids and clues in their teaching. It is important that the educator recognizes this. It is more important that the educator respects the fact that all learners do not learn best through visual learning methods and may have a preferred learning style that is quite different from the educator.

The next phase of this process of enhancing instruction is finding out how the diverse individuals prefer to learn. The educator should assess the dominant or preferred learning styles of the diverse

1. This document is FCS9226, one of a series of the Family Youth and Community Sciences Department, Florida Cooperative Extension Service, Institute of Food and Agricultural Sciences, University of Florida. Original publication date September 2005. Visit the EDIS Web Site at http://edis.ifas.ufl.edu

2. Lisa A. Guion, Ed.D., associate professor, Department of Family, Youth and Community Sciences, Florida Cooperative Extension Service, Institute of Food and Agricultural Sciences, University of Florida, Gainesville FL 32611.

The Institute of Food and Agricultural Sciences (IFAS) is an Equal Opportunity Institution authorized to provide research, educational information and other services only to individuals and institutions that function with non-discrimination with respect to race, creed, color, religion, age, disability, sex, sexual orientation, marital status, national origin, political opinions or affiliations. U.S. Department of Agriculture, Cooperative Extension Service, University of Florida, IFAS, Florida A. \& M. University Cooperative Extension Program, and Boards of County Commissioners Cooperating. Larry Arrington, Dean 
clientele he/she is trying to serve through his/her program.

There are two methods for determining the preferred learning style(s) of a group. The first is outlined in this paper and is time intensive. This article will outline some steps for learning about the clientele and their preferred ways of learning. The other strategy is to consult the literature on preferred cultural learning styles. Then, validate whether the individuals he/she is working with share that general, observed (empirically tested) cultural group's preferred learning style. Validation can occur via the usage of cultural brokers or by surveying (telephone, written, email, etc.) a small, representative sample of the targeted clientele to determine whether the cultural learning style preference holds true for the majority of them. The work of Guion et. al. (2003) provides a summary of the literature on cultural learning style preferences for the four main ethnic groups: African American, Asian American, Hispanic/Latino American, and Native American.

The final phase of the process to enhance instruction is a continual integration of various cultural learning styles into the learning process. Essentially, this is referred to in the literature as culturally appropriate instruction. It is also called, to a lesser degree, culturally responsive instruction.

\section{Benefits of Culturally Appropriate Instruction}

- Increases participation in a program. Individuals are more likely to participate and to attend future programs if they feel that the material taught was valuable and meaningful to them.

- Increases interest in a topic. The attention span is extended when information is taught via the learner's preferred learning style.

- Enhances learning of the subjects taught. There is an increase in knowledge of the subject taught when learners receive education in a way they can readily process and understand.

- Shows respect for their culture. Developing teaching strategies that take into account preferred cultural learning styles demonstrates a true commitment to education and respect for the culture. It takes the emphasis away from the educator (what the educator likes to do, his/her preferences) and focuses on what will enhance learning.

- Shows commitment to planning programs for a diverse audience. Takes cultural diversity from an occasional thought to a natural, ongoing part of the planned learning process.

\section{Key Components for Culturally Appropriate Instruction}

There are several key components that are necessary to enhance instruction in order to connect with diverse audiences:

1. Developing a clear sense of your own cultural identity.

2. Learning about the cultural backgrounds and experiences of diverse individuals you work with or desire to work with.

3. Learning how to be a competent and effective cross-cultural communicator.

4. Becoming cognizant of the divergent styles of thinking and learning of diverse populations.

5. Recognizing the needs, preferences, strengths, and experiences of individuals from diverse cultures.

6. Incorporating culturally relevant curriculum materials and instructional aids.

7. Using multiple modes of teaching to accommodate different learning styles.

8. Having positive expectations of all students.

9. Encouraging community involvement as well as parental involvement.

\section{Learning About Your Clientele, Their Families, and Communities}

Below are some strategies that you can use to learn about the culture of your targeted clientele so that you can make your instruction more culturally 
appropriate. These strategies focus on more direct, interpersonal methods.

- Engage families in programming from conception to implementation. Contact the immediate and extended kinship groups of the targeted individuals, then seek their involvement in program planning, design, and implementation.

- Get involved in activities and events that are important in the community. This will allow you to see how these events are carried out and how information is conveyed and transmitted. This will provide ideas for you as you plan programs for that particular audience.

- Get assistance and support from opinion leaders, gatekeepers, and informal leaders. Use them as cultural brokers who can assist you in planning the learning experiences that will be best received.

- Assemble a focus group of individuals from the target audience to gain insight into their learning styles.

- Pilot test a lesson using various learning approaches, then assess which approach is most effective.

\section{Culturally Relevant Educational Materials}

In addition to making sure that the teaching methods and strategies you employ reflect the cultural learning style preference of the targeted audience, it is equally important that the educational materials be culturally relevant and inclusive. Some educators may contend that a curriculum, lesson or other educational aid does not need to be customized to different ethnic/cultural groups. For example, some may feel that the principles that guide good parenting are the same for all humans, so a specific curriculum targeting a certain ethnic/cultural group is unwarranted. Others might adamantly object and feel that this position advocates a "one size fits all" approach.
This author acknowledges the fact that most basic principles that are addressed in Extension subject areas apply to all individuals, such as what constitutes proper nutrition, good money management practices, and so forth. However, the literature clearly suggests that due to different cultural norms, values, beliefs, practices, and traditions within a given ethnic group, the way the principles are presented and taught in the curriculum may need to vary in order to effectively reach diverse audiences (Allison, 2003, Villegas and Guion, et. al., 2003; Lucas, 2002; McCarthy, C. 1994; Shade, 1997; Sleeter, 1992; Sparks, 2000). Therefore, educators should identify resources for teaching specific subject matter through culturally and ethnically diverse curricula, lessons, games, and activities. Before choosing any curriculum or educational resource for a specific group, an educator should ask the following questions:

1. Is the content accurate and research-based?

2. Is the material written at a reading level appropriate for the audience?

3. Are the applications and activities appropriate for the needs of the audience?

4. Does the curriculum cover issues/topics on the subjects that are important to the audience?

5. Does it provide interesting application exercises for applying the ideas?

6. Are the examples relevant to the life experiences of the audience?

7. Does the content reflect the norms, values, and preferences of the target audience and avoid negative stereotyping?

8. When related to the subject content, are the cultural observances acknowledged and/or celebrated?

9. Does the curriculum involve users as partners in applying the principles taught in the lessons to their lives? 


\section{Conclusion}

Educators must transition from teaching all groups using the same methods and educational materials. Certain teaching styles and learning aids that are appropriate for one group may not be appropriate for a group from a different cultural background. In groups where there are mixed styles of preferred learning, there should be mixed teaching methods and use of mixed educational materials. It may be difficult given time constraints, responsibility for multiple programs, under staffing, etc., however small steps can and should be taken to build classrooms where all participants have the optimum chance of learning.

\section{References}

Allison, B.N. (2003). Multicultural classrooms: Implications for family and consumer sciences teachers. Journal of Family and Consumer Sciences, 95(2), 38-43.

Banks, J. A., Cookson, P., Gay, G., \& Whawley, W. D. (2001). Diversity within unity: Essential principles for teaching and learning in a multicultural society. Phi Delta Kappan, 83(3), 196-210.

Guion, L. A., Goddard, H. W., Broadwater, G., Chattaraj, S., \& Sullivan-Lytle, S. (2003). Strengthening programs to reach diverse audiences. Gainesville, FL: Florida Cooperative Extension, University of Florida.

McCarthy, C. (1994). Multicultural discourses and curriculum reform: A critical perspective. Educational Theory, 44(1),

Shade, B.J. (1997). Culture, style and the educative process. Springfield, IL: Thomas Publishing.

Sleeter, C. E. (1992). Restructuring schools for multicultural education. Journal of Teacher Education, 43(2), 141-148.

Sparks, S. (2000, May). Classroom and curriculum accommodations for Native American students. Intervention In School And Clinic, 35(5), 259-263.
Villegas, A.M. \& Lucas, T. (2002). Preparing culturally responsive teachers: rethinking the curriculum. Journal of Teacher Education, 53(1), 20-43.

\section{EDIS Fact Sheets in the Planning Culturally Relevant Programs Series}

1. Guion, L.A. (2005). An Overview of Diversity [Online]. EDIS. Florida Cooperative Extension Service, University of Florida. http://edis.ifas.ufl.edu/FY752

2. Guion, L.A. (2005). Reaching Diverse Audiences [Online]. EDIS. Florida Cooperative Extension Service, University of Florida. http://edis.ifas.ufl.edu/FY753

3. Guion, L.A., \& Brown, K. (2005). Culturally Competent Extension Educators [Online]. EDIS. Florida Cooperative Extension Service, University of Florida. http://edis.ifas.ufl.edu/FY754

4. Guion, L.A., \& Harper Golden, J. (2005). Culturally Diverse Advisory Boards and Volunteers [Online]. EDIS.Florida Cooperative Extension Service, University of Florida. http://edis.ifas.ufl.edu/FY755

5. Guion, L. A., \& Walker, N. (2005). Planning Programs to Break Down Cultural Barriers [Online]. EDIS. Florida Cooperative Extension Service, University of Florida. http://edis.ifas.ufl.edu/FY756

6. Guion, L. A. (2005). Personal Marketing: A Strategy for Marketing Programs to Diverse Audiences [Online]. EDIS. Florida Cooperative Extension Service, University of Florida. http://edis.ifas.ufl.edu/FY757

7. Guion, L. A.,\& Kent, H. (2005). Ethnic Marketing: A Strategy for Marketing Programs to Diverse Audiences [Online]. EDIS. Florida Cooperative Extension Service, University of Florida. http://edis.ifas.ufl.edu/FY758

8. Guion, L. A., \& Kent, H. (2005). Relationship Marketing: A Strategy for Marketing Programs to Diverse Audiences [Online]. EDIS. Florida 
Cooperative Extension Service, University of

Florida. http://edis.ifas.ufl.edu/FY759

9. Guion, L.A., \& Harper Golden, J. (2005).

Maximizing The Assets Of A Diverse Community

[Online]. EDIS. Florida Cooperative Extension

Service, University of Florida.

http://edis.ifas.ufl.edu/FY760

10. Guion, L. A. (2005). Enhancing Instruction

To Connect With Diverse Audiences [Online]. EDIS.

Florida Cooperative Extension Service, University of

Florida. http://edis.ifas.ufl.edu/FY761 